\title{
Diel vertical migration of copepods and its environmental drivers in subtropical Bahamian blue holes
}

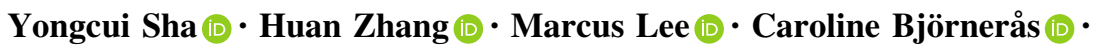 \\ Martin Škerlep (D) - Raphael Gollnisch (1) - Simon David Herzog (1) • \\ Gustaf Ekelund Ugge (D) - Jerker Vinterstare (D) Nan Hu • Varpu Pärssinen (1) • \\ Kaj Hulthén (1) - P. Anders Nilsson $(1)$ - Karin Rengefors $(1) \cdot$ Christer Brönmark $(1)$ \\ R. Brian Langerhans $\mathbb{D} \cdot$ Lars-Anders Hansson $(\mathbb{D}$
}

Received: 29 June 2020/ Accepted: 21 October 2020/Published online: 2 November 2020

(C) The Author(s) 2020

\begin{abstract}
Diel vertical migration (DVM) is the most common behavioral phenomenon in zooplankton, and numerous studies have evaluated DVM under strong seasonality at higher latitudes. Yet, our understanding of the environmental drivers of DVM at low latitudes, where seasonal variation is less pronounced, remains limited. Therefore, we here examined patterns of vertical distribution in copepods in six subtropical Bahamian blue holes with different food web structure and tested the role of several key environmental variables potentially affecting this behavior. Day and night samplings showed that copepods generally performed DVM, characterized by downward migration to deeper depths during the day and upward migration to surface waters at night. Across all blue holes, the daytime vertical depth distribution of
\end{abstract}

Handling Editor: Télesphore Sime-Ngando

Y. Sha $\cdot$ H. Zhang · M. Lee · C. Björnerås ·

M. Škerlep · R. Gollnisch · S. D. Herzog ·

G. Ekelund Ugge · J. Vinterstare .

N. Hu · V. Pärssinen · K. Hulthén .

P. A. Nilsson - K. Rengefors · C. Brönmark ·

L.-A. Hansson ( $\square)$

Department of Biology, Aquatic Ecology, Lund

University, Lund, Sweden

e-mail: lars-anders.hansson@biol.lu.se

H. Zhang

Institute of Hydrobiology, Chinese Academy of Sciences,

Wuhan, People's Republic of China calanoid copepods correlated positively with both predation risk and depth of food resources (Chlorophyll $a$ ), but was less affected by ultraviolet radiation (UVR). A potential explanation is that since UVR is a continuous threat across seasons, zooplankton have established photoprotective pigmentation making them less vulnerable to this threat. The copepods also showed a size-structured depth segregation, where larger individuals were found at deeper depths during the day, which further strengthens the suggestion that predation is a major driver of DVM in these systems. Hence, in contrast to studies performed at higher latitudes, we show that despite the constant exposure to UVR, predator avoidance and food availability are the most pronounced drivers of copepod DVM at those low latitudes, suggesting that the main driver of DVM

\section{G. Ekelund Ugge}

School of Bioscience, University of Skövde, Skövde, Sweden

K. Hulthén · R. B. Langerhans

Department of Biological Sciences and W.M. Keck

Center for Behavioral Biology, North Carolina State

University, Raleigh, NC, USA

P. A. Nilsson

Department of Environmental and Life Sciences, Karlstad

University, Karlstad, Sweden 
may vary among systems, but also systematically by latitude.

Keywords Calanoid copepod - Cyclopoid copepod . Vertical distribution - Predation · Food availability . Ultraviolet radiation $\cdot$ Blue hole $\cdot$ Bahamas

\section{Introduction}

Diel vertical migration (DVM) is a widespread phenomenon, documented in diverse zooplankton taxa across freshwater and marine ecosystems (Hays 2003). DVM generally describes the spatiotemporal distribution pattern where zooplankton exhibit a significant change in their depth distribution following a daily rhythm, that is typically characterized by downward migration to deep waters during the day and upward migration to surface waters at night (Hays 2003; Lampert 1989). Such massive daily movement of animals was first described by Cuvier in 1817 (Bayly 1986) and has since inspired numerous ecological and evolutionary studies aimed at addressing its underlying mechanisms.

Predator avoidance is generally considered as the ultimate reason for DVM (Hays 2003; Lampert 1993), as zooplankton, which constitute potential prey for numerous organisms, can escape from visually oriented predators by avoiding surface waters during the day. Previous studies have demonstrated that the strength of DVM in zooplankton can be tightly linked to the abundance of planktivorous fish in the environment (Loose 1993; Loose and Dawidowicz 1994; Ringelberg 1991). Moreover, due to the higher risk of detection by visually hunting predators, larger zooplankton tend to show a stronger DVM behavior by migrating to deeper depths during the day as compared to smaller species and/or individuals (Brooks and Dodson 1965). Previous studies, primarily at higher latitudes or high-elevation systems, have demonstrated that zooplankton, including the freshwater cladoceran Daphnia (Ekvall et al. 2015; Hansson and Hylander 2009b) and copepods (Tiberti and Barbieri 2011; Tiberti and Iacobuzio 2013), perform sizestructured migration when exposed to visually oriented fish predators, where larger individuals generally reside at greater depths during the day compared to smaller conspecifics.
DVM has however also been observed in lakes with no major predation on zooplankton. This is particularly true for systems with more transparent waters (Leech and Williamson 2001; Rhode et al. 2001), indicating an important role of ultraviolet radiation (UVR) in determining the daytime vertical distribution of zooplankton (Hansson and Hylander 2009a; Williamson et al. 2011). When dwelling in the surface waters, the high exposure to UVR may lead to DNA damage, impaired reproduction, and higher mortality in zooplankton (Hansson and Hylander 2009a). As UVR attenuates with depth (Scully and Lean 1994), downward migration during daytime provides a refuge for zooplankton to minimize the UVR damage. Both predation risk and UVR threats vary considerably between day and night, and both are potentially mitigated by organisms through altering their vertical position in the water column. It is therefore often difficult to disentangle the ultimate cause of DVM. To this end, Williamson et al. (2011) developed a comprehensive theory known as the transparencyregulator hypothesis (TRH). The TRH argues that in more productive but less transparent lakes, predation is more important in regulating downward migration, while in more transparent lakes with fewer fish, UVR may act as the primary driver of DVM. Furthermore, factors such as temperature and food availability, that may vary little over the diurnal cycle, are additional important factors in determining the optimal depth for individuals to achieve maximal fitness and growth rate (Williamson et al. 2011). Such food-related DVMs may be expected to be of specific importance in lakes offering low algal food resources for zooplankton, or where the algae are also migrating to specific depths.

To date, an extensive number of studies on DVM have been performed in high-latitude and high-elevation lakes. However, our knowledge regarding the vertical distribution of zooplankton in low-latitude freshwater systems remains poor, as few studies have addressed the potential mechanisms underlying zooplankton DVM in subtropical or tropical freshwater environments (Rejas et al. 2007; Zaret and Suffern 1976). Unlike at high latitudes, where the intensity of UVR varies significantly across seasons, being strongest during summer, but completely absent during winter, these subtropical systems are constantly exposed to direct solar radiation throughout the year, i.e., variable among seasons but never absent. Similarly, at high latitudes, fish typically reproduce once 
per year, suggesting a short duration of predation pressure imposed on zooplankton. However, at low latitudes, fish are fractional spawners that reproduce several times during a year, and therefore zooplankton prey are subject to more constant predation risk throughout the year. The ecological and environmental differences between high- and low-latitude systems make it difficult to predict the potential drivers of zooplankton DVM in subtropical systems only based on comparisons with their high-latitude counterparts. Therefore, we set out to characterize the diel distribution patterns of zooplankton in a set of subtropical lakes ("blue holes") on Andros Island, The Bahamas, where UVR exposure is intense and constantly present over the year and predation pressure differs naturally among replicate blue holes.

Bahamian blue holes are natural, water-filled vertical caves, found in carbonate banks and islands, that typically have a freshwater lens overlying marine ground water (Mylroie et al. 1995). These isolated aquatic systems represent temporally stable environments and generally support relatively simple, but different, fish communities. Some blue holes harbor only planktivorous fish, while others have both planktivorous and piscivorous fish (Heinen et al. 2013), corresponding to high- and low-predation risk for zooplankton. Therefore, these unique systems provide a natural laboratory and a rare opportunity to assess zooplankton DVM and its key environmental drivers in the subtropics.

We conducted a detailed analysis of the vertical distribution of copepods during day and night in a set of subtropical Bahamian blue holes that vary in predation pressure (due to different fish assemblages) and water transparency, and thereby differ in UVR exposure of aquatic organisms. First, we compared the daytime and nighttime distributions of copepods in blue holes to investigate whether they perform DVM behavior. Second, we tested for size-structured migration, where we predicted that larger copepod individuals would reside at deeper depths during the day. Third, we tested relationships between variation in predation pressure, UVR threat, and food availability with the daytime vertical distribution of calanoid copepods to identify primary drivers of DVM. We also related our results to the TRH (Williamson et al. 2011), which predicts a positive correlation between zooplankton depth distribution and predation risk if predation is a primary driver of DVM. In contrast, if
UVR is the most important factor, DVM should depend on the water transparency, resulting in pronounced migration in clear but not in turbid blue holes.

\section{Material and methods}

\section{Study sites}

Zooplankton were sampled from six blue holes located on Andros Island, The Bahamas, with surface diameters ranging from 58 to $90 \mathrm{~m}$ and freshwater depth ranging from 10 to $31 \mathrm{~m}$ (Table 1, Fig. 1). These sites differ in fish communities, where three blue holes (Cousteau's, Stalactite, and West Twin, Table 1, Fig. 1) harbor both a piscivorous fish (Bigmouth sleeper, Gobiomorus dormitor) and a relatively low density of a planktivorous fish (Bahamas mosquitofish, Gambusia hubbsi) (Heinen et al. 2013). Therefore, we expected zooplankton prey in these three blue holes to experience a relatively low predation risk. In contrast, the other three blue holes (Hubcap, Rainbow, and East Twin) harbor higher densities of the planktivorous fish without any piscivorous fish (Heinen et al. 2013), and, hence, we expected zooplankton prey in these blue holes to suffer from relatively high predation risk. In addition to these broad expectations of variable predation risk to zooplankton in the blue holes, we further quantified predation risk based on feeding rates of $G$. hubbsi (see as follows).

\section{Sampling}

To quantify copepod distribution patterns within each blue hole, we collected zooplankton from six depths at 1 to $5 \mathrm{~m}$ depth intervals from the water surface $(0.4 \mathrm{~m})$ to the top layer of the halocline, i.e., within the freshwater layer (Table 1). The depth intervals were determined by dividing the freshwater depth by five and then rounding down to the closest meter. As no zooplankton individuals were ever detected in samples taken below the halocline (personal observations), we therefore excluded this zone from further analyses. In four blue holes (Hubcap, Rainbow, Stalactite, and Cousteau's), triplicate samples were taken with a $2 \mathrm{~L}$ Limnos water sampler (Limnos, Finland) at each depth during midday (day) and two hours after sunset (night) in March 2018. For the other two blue holes (West Twin and East Twin), six water samples were 
Table 1 Location and main characteristics of the blue holes examined in the study. Predation risk was estimated as the daytime average number of bites per minute by adult
Gambusia hubbsi per $\mathrm{m}^{3}$. Note that G. hubbsi (Gambusia hubbsi) is planktivorous and G. dormitor (Gobiomorus dormitor) is piscivorous

\begin{tabular}{llllllll}
\hline Blue hole & $\begin{array}{l}\text { Latitude } \\
\left({ }^{\circ} \mathrm{N}\right)\end{array}$ & $\begin{array}{l}\text { Longitude } \\
\left({ }^{\circ} \mathrm{W}\right)\end{array}$ & $\begin{array}{l}\text { Surface } \\
\text { diameter }(\mathrm{m})\end{array}$ & $\begin{array}{l}\text { Freshwater } \\
\text { depth }(\mathrm{m})\end{array}$ & $\begin{array}{l}\text { Secchi } \\
\text { depth }(\mathrm{m})\end{array}$ & $\begin{array}{l}\text { Predation } \\
\text { risk }\end{array}$ & Fish community \\
\hline Rainbow & 24.785 & 77.860 & 90 & 12 & 6.97 & 0.289 & G. hubbsi \\
Stalactite & 24.785 & 78.017 & 58 & 31 & 15.72 & 0.332 & G.hubbsi, G. dormitor \\
Hubcap & 24.776 & 77.858 & 74 & 10 & 4.30 & 0.152 & G. hubbsi \\
Cousteau's & 24.776 & 77.916 & 68 & 20 & 8.70 & 0.172 & G.hubbsi, G. dormitor \\
East Twin & 24.752 & 78.006 & 63 & 27 & 5.70 & 1.590 & G. hubbsi \\
West Twin & 24.753 & 78.009 & 69 & 22 & 7.90 & 0.423 & G.hubbsi, G. dormitor \\
\hline
\end{tabular}

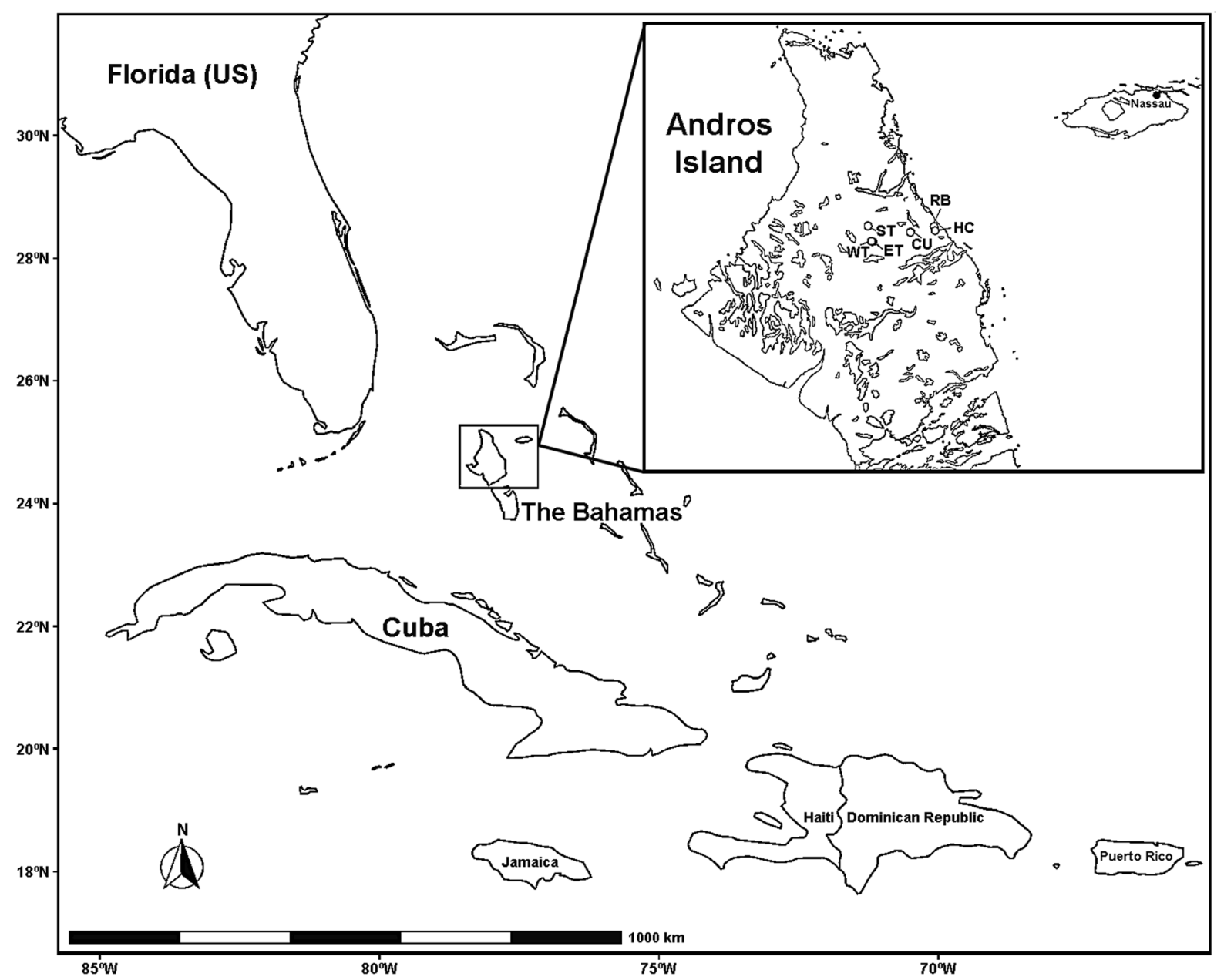

Fig. 1 Location of the studied blue holes on Andros Island, the Bahamas. RB Rainbow, ST Stalactite, $H C$ Hubcap, $C U$ Cousteau's, ET East Twin, and WT West Twin. Modified from Björnerås et al. (2020) 
collected during midday at each depth using a $1 \mathrm{~L}$ Ruttner water sampler (KC, Denmark) in June 2019. To ensure consistent analysis across all sites even though different water sampler volumes were employed, the $1 \mathrm{~L}$ water samples collected from West Twin and East Twin were pooled into three sets of $2 \mathrm{~L}$ samples for each depth in each site so that zooplankton were examined in three $2 \mathrm{~L}$ units at each depth for all blue holes. However, we only surveyed five depths, not six, for West Twin as we could not get the samples from the deepest depth because we generally hit the bottom and disturbed the water at the desired depth due to the complex bottom topography.

Zooplankton were transferred from water samples to $50 \mathrm{ml}$ bottles and preserved with 5-10 drops of glycerol and $20 \mathrm{ml} 95 \%$ ethanol after filtering each $2 \mathrm{~L}$ water sample through a $50 \mu \mathrm{m}$ mesh filter. All samples were stored in a refrigerator before counting and body length measurements. Zooplankton were counted in a petri dish with eight sub-chambers, each $26 \times 33 \mathrm{~mm}$ (Nalge Nunc, USA) using a Dino-Lite Edge X $200 \times$ (USB3) microscope (AnMo Electronics Corporation, Taiwan) and a stereomicroscope (Olympus SZX7, Japan) at 10-30 $\times$ magnification. Individuals were categorized into calanoid copepods and cyclopoid copepods and counted separately. Body lengths, measured from the tip of the head to the end of the furca, were taken for the first 10 observed copepod individuals within each $2 \mathrm{~L}$ sample. Individuals in nauplius stage were excluded from the numeration and length measurements.

At each daytime sampling, we also measured the vertical profiles of temperature and Chlorophyll $a$ using a CTD probe (AAQ1186s-H, Alec Electronics, Japan) and the water transparency (Secchi depth) using a Secchi disk $(20 \mathrm{~cm}$ diameter with alternating black and white sections). We used the Secchi depth as a proxy for UVR transparency for each site, assuming that a large Secchi depth indicates high UVR transparency, i.e., a high potential role of UVR for zooplankton DVM.

\section{Predation threat}

In addition to the classification of blue holes into highand low-predation risk based on the density of planktivorous fish, we also estimated the predation threat imposed on zooplankton by $G$. hubbsi in each blue hole by calculating daytime feeding rate per site using previously collected data. Heinen et al. (2013) showed geographic variation in both adult $G$. hubbsi feeding rate and density among blue holes. To estimate daytime predation risk to zooplankton at each site, we calculated the product of the average feeding rate of male and female G. hubbsi and their average offshore density (where most zooplankton reside), resulting in an overall index of predation risk (number of bites from adult G. hubbsi per minute per $\mathrm{m}^{3}$ ). Feeding rate and density were measured using in situ underwater visual observations during midday (see details in Heinen et al. (2013)), and we included data from Heinen et al. (2013), as well as additional surveys performed subsequently by the same person (RBL see author list) using the same methods (2 years per site for feeding rates, 4-6 years per site for densities).

\section{Data analysis}

All statistics were performed using R, version 3.5.0 ( $\mathrm{R}$ Core Team 2018). In order to evaluate zooplankton DVM behavior, we examined differences in zooplankton abundances over depths between day and night using a linear mixed-effects model (lme function in nlme package, (Pinheiro et al. 2018)). We ran the model separately for each of the four blue holes (Hubcap, Rainbow, Stalactite, and Cousteau's). For each model, sample time (day/night) and depth (six depths) were used as fixed factors and the $2 \mathrm{~L}$ sample ID served as a random factor. A significant effect of the interaction between sample time and depth was used to verify the existence of DVM behavior.

Daytime weighted mean depth (WMD) was calculated for both calanoid and cyclopoid copepods for each site using the Worthington (Worthington 1931) formula: $\mathrm{WMD}=\sum\left(d_{i} n_{i}\right) / \sum\left(n_{i}\right)$, where $d_{i}$ is the depth of the $i$ sample and $n_{i}$ is the number of organisms caught at $d_{i}$. Since surveyed depths were different across sampled blue holes (Fig. 3), sampled depths at each site were normalized to percentage of the respective maximum depth. Normalized values, i.e., $0-100$, were then used in the mean depth calculations. Moreover, the number of organisms was also logtransformed $\left(n_{i}+1\right.$, to account for any zeros) before the calculation of WMD. We also calculated the weighted mean Chlorophyll $a$ depth using the normalized depth for each site. This value was calculated 
using the same formula as above but here $n_{i}$ is the Chlorophyll $a$ concentration at each depth $d_{i}$.

We used simple linear regression analyses to examine the relationships between daytime WMD of calanoid copepods and the environmental variables predation risk, weighted mean Chlorophyll $a$ depth, and UVR transparency (Secchi depth) across blue holes (Hubcap, Rainbow, Stalactite, East Twin, and West Twin). Only calanoid copepods were considered in the regression analysis because not all of our investigated blue holes had comparable densities of cyclopoid copepods. Since we only found cyclopoid copepods in Cousteau's, it was not included in the regression analysis. Moreover, calanoid copepods are twice as large as cyclopoid copepods and are expected to experience higher risk to fish predation as suggested by Gluckman and Hartney (2000), who found that calanoid copepods contributed more to G. hubbsi's diet than cyclopoid copepods. Therefore, we have focused our analyses on calanoid copepods in order to better evaluate the potential role of fish predation in regulating zooplankton vertical migration in lowlatitude systems.

The size distribution of calanoid copepods in the water column was analyzed in the daytime samples from five blue holes (Hubcap, Rainbow, Stalactite, East Twin, and West Twin). We separated the water column into three hypothetical depth layers, including surface, middle, and deep, where surface layer included depths that were shallower than half of the Secchi depth, middle layer included depths that were deeper than half of the Secchi depth but shallower than the Secchi depth, and the remaining depths were assigned to deep layer. The influence of depth layer on zooplankton size distribution was analyzed using a linear mixed-effects model (lme function in nlme package, (Pinheiro et al. 2018)), where the depth layer was used as a fixed factor and the $2 \mathrm{~L}$ sample ID nested in sampling sites (blue holes) served as a random factor. Tukey's HSD post hoc test was performed to compare differences in average zooplankton body size between the depth layers. We assumed that large-sized zooplankton would stay at deeper depths during the day compared to smaller individuals when exposed to fish predators, whereas all size classes of zooplankton would migrate downward to deeper depths when UVR was the major driver for DVM.

\section{Results}

Basic limnological features

All studied blue holes were stratified in a freshwater layer, with surface temperatures ranging from $24.6{ }^{\circ} \mathrm{C}$ to $26.2{ }^{\circ} \mathrm{C}$, above the halocline. In the freshwater layer, which is the focus of our study, there was a weak thermal gradient throughout the water column during the day with a maximum of $2.8^{\circ} \mathrm{C}$ difference between surface and deep waters (Fig. 2a). Average Chlorophyll a concentrations were generally very low $\left(<0.7 \mu \mathrm{g} \mathrm{L}^{-1}\right)$, except in Hubcap, which had an average of $1.34 \mu \mathrm{g} \mathrm{L}^{-1}$. All blue holes had a deep chlorophyll maximum just above the halocline, especially in East Twin where the average Chlorophyll

(a)

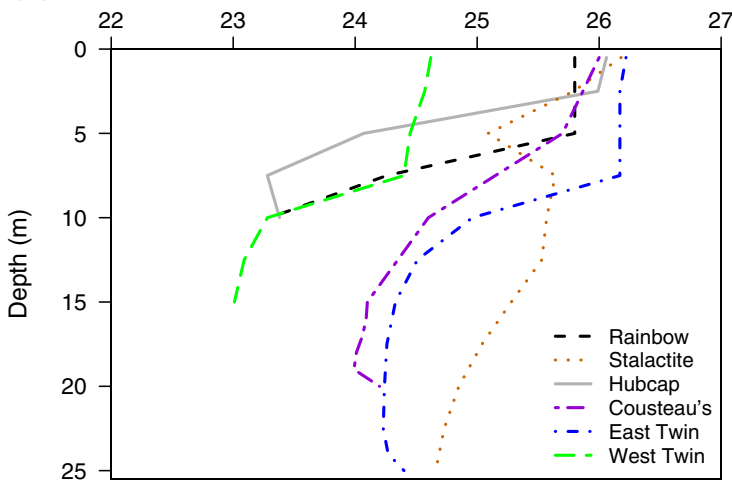

(b)

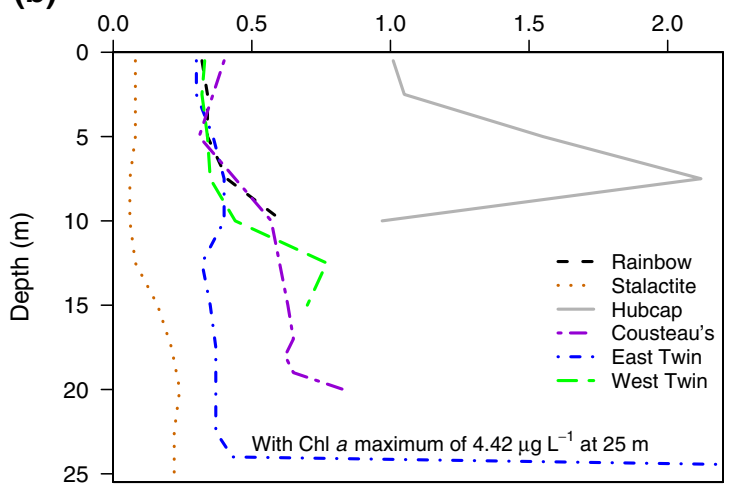

Fig. 2 Temperature (a) and Chlorophyll $a$ (b) profiles of the six Bahamian blue holes. The end of each line indicates the depth of the halocline in that specific blue hole. Below that depth oxygen levels are very low and no zooplankton were ever detected here. Note that Chlorophyll $a$ concentration for East Twin at $25 \mathrm{~m}$ is $4.42 \mu \mathrm{g} \mathrm{L}^{-1}$, which is, for clarity, not shown in the figure 
$a$ concentration in the deepest three meters $\left(1.74 \mu \mathrm{g} \mathrm{L}^{-1}\right)$ was around six times higher than that at the surface $\left(0.30 \mu \mathrm{g} \mathrm{L}^{-1}\right)$ (Fig. 2b). The estimated UVR transparency varied considerably among blue holes and the Secchi depth ranged from 15.72 to $4.30 \mathrm{~m}$ and was highest in Stalactite, followed by Cousteau's, West Twin, Rainbow, East Twin, and lowest in Hubcap (Table 1). Moreover, the predation threat also differed between blue holes, with copepods being under highest predation threat in East Twin and lowest in Cousteau's (Table 1).

\section{Copepod abundances}

Copepods from two orders, Calanoida and Cyclopoida, were detected in the six investigated blue holes. Mean abundance of calanoid copepods was higher (22.6 ind. $\mathrm{L}^{-1}$ ) than cyclopoid copepods (6.8 ind. $\mathrm{L}^{-1}$ ) across the six blue holes. In Cousteau's, we only found cyclopoid copepods with a mean abundance of 14.8 ind. $\mathrm{L}^{-1}$ in the whole water column, whereas both calanoid and cyclopoid copepods coexisted in the other five blue holes, but in different proportions. Specifically, calanoid copepods were dominant in the blue holes of Rainbow, Stalactite, and West Twin, whereas high densities of cyclopoid copepods were found in Hubcap and East Twin.

Diel vertical migration

We found significant evidence for DVM in all four blue holes for which we conducted both day and night sampling (Table 2), but the nature of the migration was not uniform across all sites. Calanoid copepods in Rainbow (Fig. 3a) and Stalactite (Fig. 3b), and cyclopoid copepods in Hubcap (Fig. 3f) and Cousteau's (Fig. 3g) performed DVM (time $\times$ depth interaction $p<0.001$, Table 2). In Rainbow, Stalactite, and Cousteau's, these copepods avoided surface waters and preferred to occupy intermediate depths during the day, but ascended higher in the water column and tended to favor the surface waters during the night. However, there were several exceptions to this general pattern: (1) In Rainbow, some individuals in the adult stage resided at deeper depths during the night (Fig. 3a), (2) in Hubcap, cyclopoid copepods showed an almost uniform distribution throughout the water column during the day, and migrated upward to the water surface during the night (Fig. 3f), and (3) calanoid copepods in Hubcap did not migrate, with individuals showing a depth preference of about $5 \mathrm{~m}$ during both day and night (Table 2, Fig. 3c).

In East Twin, calanoid copepods occurred in very low abundances and were only distributed below $15 \mathrm{~m}$ during the day (Fig. 3d), whereas cyclopoid copepods, while also occurring in low abundances, were found throughout the entire water column showing a preference for intermediate depths (between 10 and $15 \mathrm{~m}$; Fig. 3h). In contrast to East Twin, the calanoid copepods in West Twin occurred in much higher numbers and more individuals were found in the surface waters during the day (Fig. 3e). In West Twin, cyclopoid copepods were only found at 4 and $16 \mathrm{~m}$ at low abundances (Fig. 3i).

\section{Daytime vertical distribution}

Across all studied blue holes, daytime WMD of calanoid copepods was positively correlated with the predation risk (Fig. 4a, $r^{2}=0.939, n=5, p=0.006$ ). Moreover, there was also a positive correlation between the weighted mean calanoid copepod depth and the weighted mean Chlorophyll $a$ depth (Fig. 4b, $\left.r^{2}=0.806, n=5, p=0.039\right)$. However, there was no relationship between UVR threat level (Secchi depth) and the WMD of calanoid copepods during the day (Fig. 4c).

\section{Copepod size distribution}

The body size of calanoid copepods differed among depth layers during the day $\left(F_{2,285}=8.86, p<0.001\right)$. A Tukey post hoc test showed that calanoid copepods were relatively small-sized in the surface layers as compared to individuals in both the middle and deep layers during the day (Fig. 5), but there were no significant size differences between middle and deep layers ( $p>0.05$, Fig. 5).

\section{Discussion}

Diel vertical migration in zooplankton is considered to be the largest migratory movement of biomass on Earth, involving daily movements and change of vertical position of vast amounts of biomass (Hays 2003). Although this phenomenon has been extensively studied for more than a century, a majority of 
Table 2 Statistical results from linear mixed-effects models examining variation in copepod vertical distribution. Bold values indicate significant results $(p<0.050)$

\begin{tabular}{|c|c|c|c|c|c|c|}
\hline Blue hole & Copepod & Factor & Num df & Den df & $F$ & $p$ \\
\hline \multirow[t]{3}{*}{ Rainbow } & \multirow[t]{3}{*}{ Calanoid } & Sample time & 1 & 24 & 0.113 & 0.740 \\
\hline & & Depth & 5 & 24 & 2.138 & 0.095 \\
\hline & & Sample time/depth & 5 & 24 & 8.137 & $<0.001$ \\
\hline \multirow[t]{3}{*}{ Stalactite } & \multirow[t]{3}{*}{ Calanoid } & Sample time & 1 & 24 & 1.210 & 0.282 \\
\hline & & Depth & 5 & 24 & 4.409 & 0.005 \\
\hline & & Sample time/depth & 5 & 24 & 7.802 & $<0.001$ \\
\hline \multirow[t]{6}{*}{ Hubcap } & \multirow[t]{3}{*}{ Calanoid } & Sample time & 1 & 24 & 0.000 & 1.000 \\
\hline & & Depth & 5 & 24 & 7.936 & $<0.001$ \\
\hline & & Sample time/depth & 5 & 24 & 0.480 & 0.788 \\
\hline & \multirow[t]{3}{*}{ Cyclopoid } & Sample time & 1 & 24 & 0.211 & 0.650 \\
\hline & & Depth & 5 & 24 & 3.426 & 0.018 \\
\hline & & Sample time/depth & 5 & 24 & 6.822 & $<0.001$ \\
\hline \multirow[t]{3}{*}{ Cousteau's } & \multirow[t]{3}{*}{ Cyclopoid } & Sample time & 1 & 23 & 13.923 & 0.001 \\
\hline & & Depth & 5 & 23 & 11.821 & $<0.001$ \\
\hline & & Sample time/depth & 5 & 23 & 8.366 & $<0.001$ \\
\hline
\end{tabular}

the studies has been conducted in high-latitude or high-elevation waters and only a limited number of studies have investigated low-latitude freshwater systems (Rejas et al. 2007; Zaret and Suffern 1976). By taking advantage of the natural Bahamian blue hole systems, we aimed to provide novel knowledge on diel patterns of the vertical distribution of zooplankton in low-latitude environments with relatively low seasonal variation in levels of food, UVR, and predation, and thereby shed light on the underlying mechanisms behind DVM in subtropical systems.

Our day and night samplings of vertical distributions indicate that low-latitude copepods from our investigated Bahamian blue holes perform DVM, characterized by a downward migration during the day and upward migration to the surface waters at night. This finding corresponds to our a priori expectations and numerous observations in other high-latitude/ high-elevation systems (Berge et al. 2009; Fischer et al. 2015; Fortier et al. 2001; Tiberti and Iacobuzio 2013). However, this pattern was not completely uniform at all sites, with one particularly interesting case: Calanoid copepods in the Hubcap blue hole did not exhibit DVM and mainly resided at a constant depth $(5 \mathrm{~m})$ during both day and night. The lack of DVM behavior at this site might be explained by the relatively low water transparency and deeper chlorophyll maximum in this blue hole. Specifically, the Secchi depth was about $4.30 \mathrm{~m}$, showing that the threats from visually hunting fish predators and UVR may decrease to negligible levels at their preferred depth $(5 \mathrm{~m})$. Moreover, the food resource estimated as Chlorophyll $a$ peaked between 5 and $7 \mathrm{~m}$, indicating that calanoid copepods could optimize the balance between food acquisition and risk from UVR and predation by remaining stationary at the food rich medium depth, while simultaneously being relatively protected from both UVR and fish predation.

Several different factors have been shown to influence the DVM behavior of zooplankton, where visual predation and UVR are suggested to drive zooplankton migrating out of the surface waters during the day, whereas food availability and temperature may be potential factors driving the upward migration during the night (Hays 2003; Williamson et al. 2011). According to the transparency-regulator hypothesis (TRH), UVR should be more important than fish predation in determining zooplankton vertical distribution in more transparent lakes (Williamson et al. 2011). For example, previous studies show small or not detectable effects of visual predation on the vertical distribution of zooplankton in clear, UVR transparent alpine lakes (Fischer et al. 2015; Kessler et al. 2008; Tiberti and Iacobuzio 2013). Moreover, strong effects of UVR on both life-history variables and behavior have been demonstrated in cladoceran zooplankton (Fernández et al. 2018), suggesting that UVR likely has a pronounced effect on zooplankton. However, this scenario seems unlikely in this blue hole system since the daytime depth of calanoid copepods 
Fig. 3 Vertical distributions of calanoid copepods (a-e) and cyclopoid copepods (f-i) in six Bahamian blue holes during the day (white bars) and night (dark bars): (a) Rainbow, (b) Stalactite, (c, f) Hubcap, (g) Cousteau's, $(\mathbf{d}, \mathbf{h})$ East Twin*, and (e, i) West Twin*. Error bars indicate +1 standard error. The mean body size ( $\mathrm{mm}$ ) of calanoid and cyclopoid copepods is shown at the top of each figure. Very low abundances of cyclopoid copepods were found in West Twin and their body size was therefore not assessed. Black dashed lines show the Secchi depth (m). Note: *East Twin and West Twin were only investigated during the day due to logistic restrictions

\section{(a)} Calanoid (Mean size: $0.679 \mathrm{~mm}$ )

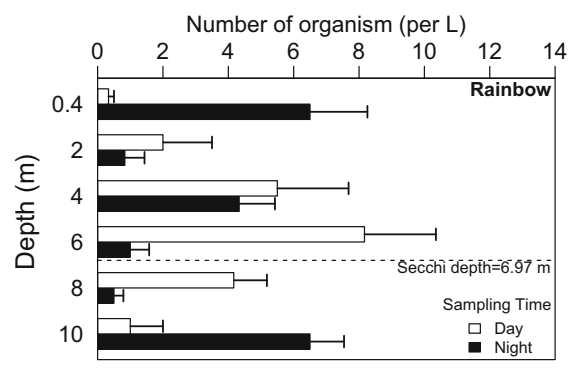

(b)

Calanoid (Mean size: $0.784 \mathrm{~mm}$ )

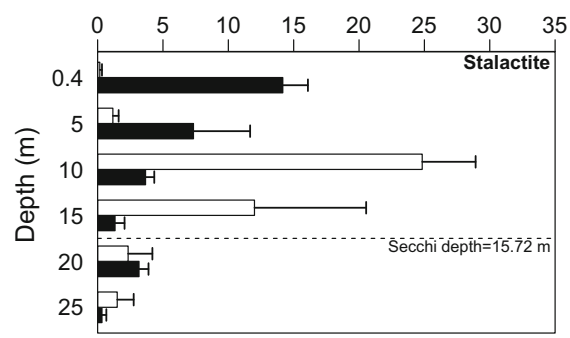

(c)

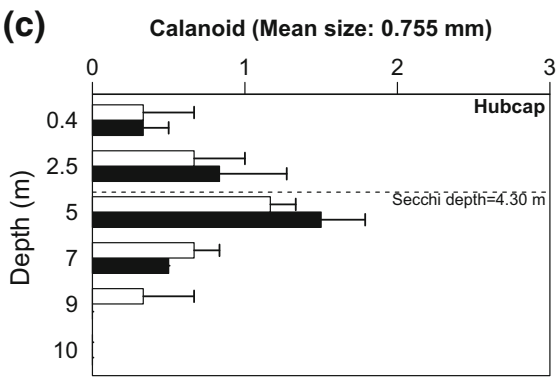

(d)

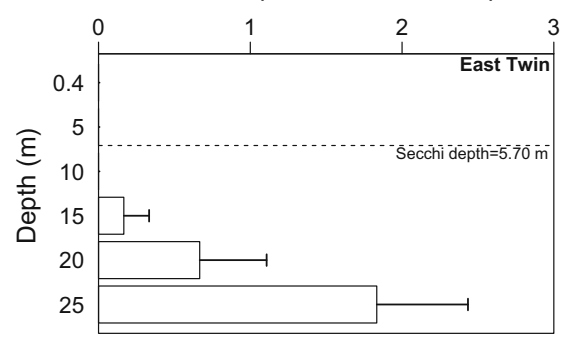

(e)

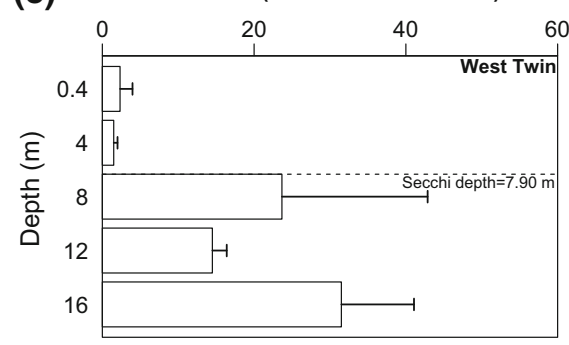

(f) Cyclopoid (Mean size: $0.408 \mathrm{~mm}$ )

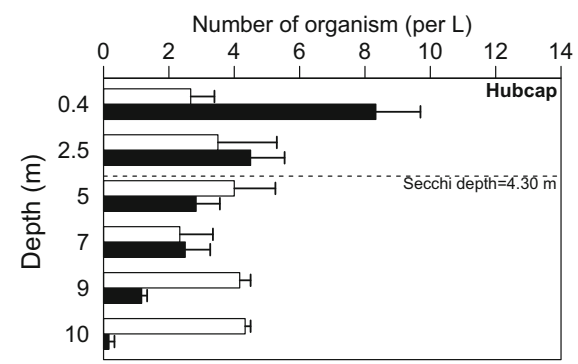

(g)

Cyclopoid (Mean size: $\mathbf{0 . 3 8 0} \mathbf{m m}$ )

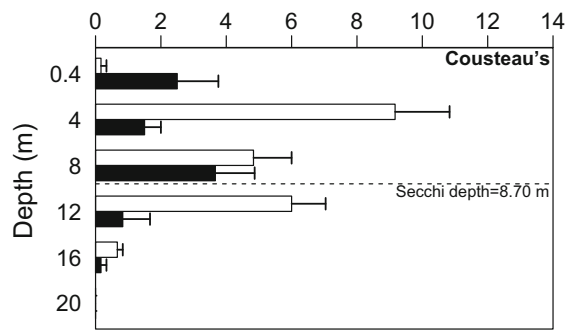

(h) Cyclopoid (Mean size: $0.293 \mathrm{~mm}$ )

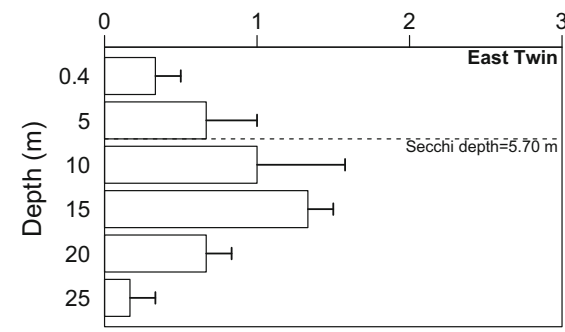

(i)

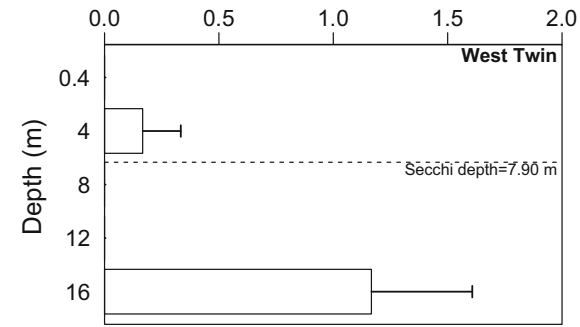



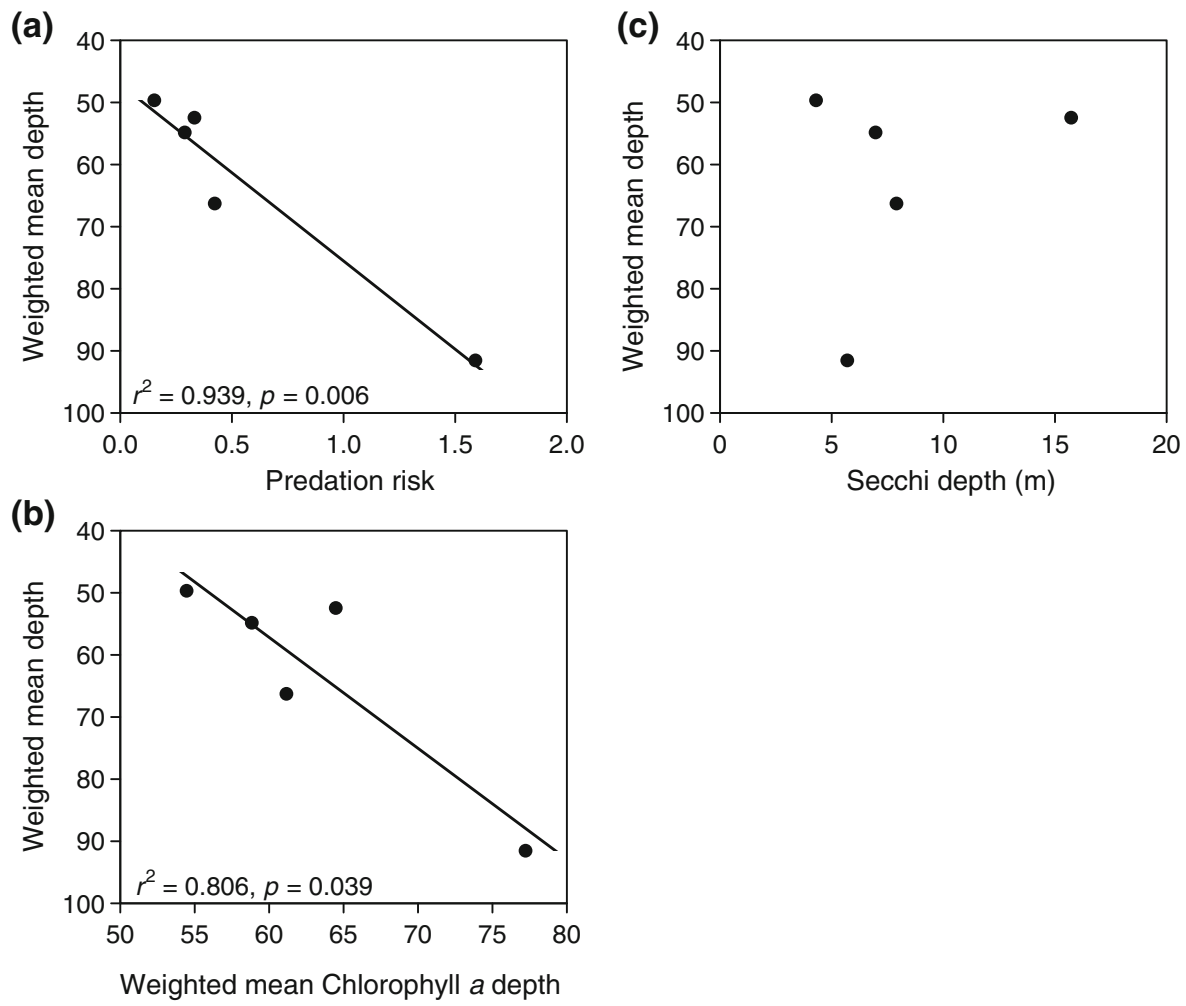

Fig. 4 Relationship between daytime weighted mean depth of calanoid copepods and predation risk (a), and weighted mean Chlorophyll $a$ depth (b), and Secchi depth (c), respectively

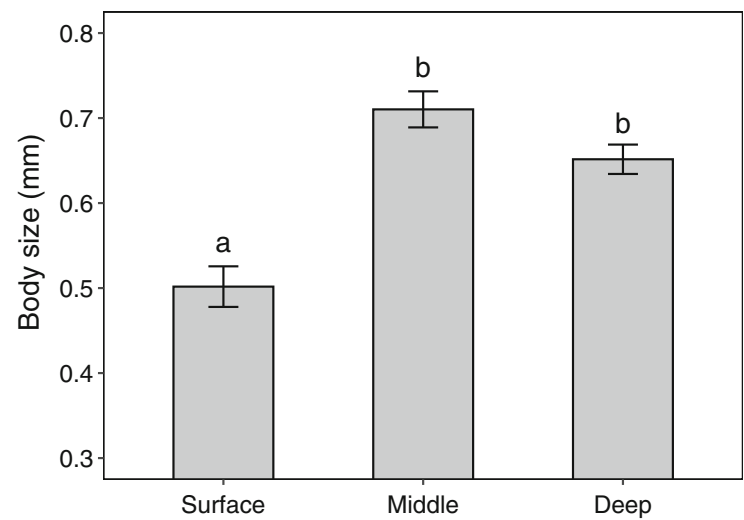

Fig. 5 Body size (mm) of calanoid copepods at surface, middle, and deep water layers during the day. Data are expressed as mean \pm 1 SE. Different letters above bars indicate significant difference

increased with both predation risk and depth of food resources (Chlorophyll $a$ ), yet was seemingly unaffected by the different UVR transparencies in the blue holes. Specifically, a large fraction of copepods was found at a depth of $10-15 \mathrm{~m}$ in Stalactite, i.e., at depths well above the Secchi depth $(15.72 \mathrm{~m})$. This suggests fish predation as a likely key environmental driver of DVM in subtropical Bahamian blue holes.

The potential role of UVR on copepod vertical distribution in our study systems seems to be negligible, which is in stark contrast to cladocerans, e.g., Daphnia, where exposure to UVR generally elicits strong behavioral responses, manifested as moving down from the surface waters (Leech et al. 2005). Similar results to ours have been demonstrated for copepods in several earlier studies. For example, Kessler et al. (2008) found no significant effect of UVR penetration on the daytime vertical distribution of calanoid copepods in alpine lakes, whereas Overholt et al. (2016) found that the magnitude of response to UVR among copepod species may vary, ranging from attraction to avoidance to no response. Moreover, some species of calanoid copepods may benefit from exposure to relatively moderate levels of UVR (Cooke and Williamson 2006), as they may use UVR as a cue to locate food resources (Martynova and Gordeeva 2010), and as exposure to UVR may also 
decrease parasite infection in copepods (Fields et al. 2014). In addition, copepods can accumulate photoprotective pigments, such as carotenoids, against UVR (Hansson and Hylander 2009a), although this comes at a cost as increased pigmentation makes copepods conspicuous, and thus, increases predation risk (Hylander et al. 2009). A recent study demonstrated that copepods exhibited higher levels of pigmentation in fishless and low-predation Bahamian blue holes, but reduced their coloration significantly in blue holes with higher predation pressure (Lee et al. 2019). Moreover, copepods may individually adjust their level of pigmentation, as well as other protective, nonpigment compounds such as mycosporine-like amino acids (Hylander 2020), to the prevailing risk from UVR and predation (Brüsin et al. 2016; Hansson 2004). While we did not, due to logistic restrictions, directly measure the amount of photoprotective compounds during our investigation, copepods residing in these blue holes that vary in both water transparency and visual predation pressure may use a cocktail of defenses, including behavior and photoprotective substances, to reduce the exposure to UVR (Hansson et al. 2007).

The positive association between mean depths of calanoid copepods and Chlorophyll $a$ suggests that structural drivers, such as food availability, are also important for the vertical distribution of zooplankton in low-latitude blue holes. This is consistent with previous studies performed in mountain lakes, where daytime vertical depth of copepods increases with the depth distribution of Chlorophyll $a$ (Fischer et al. 2015; Tartarotti et al. 2017). Temperature, another factor known to affect zooplankton depth distribution, in the blue holes was generally only a few degrees lower at deeper, compared to shallower depths. Moreover, since the lowest temperature recorded was as high as $23{ }^{\circ} \mathrm{C}$, temperature is unlikely to influence the vertical distribution of copepods in the Bahamian blue holes. Hence, our data suggest that copepods in the blue holes of Bahamas optimize their vertical distribution by residing at a depth where visual predation is minimized, but food resources still remain relatively high.

DVM is an important strategy for zooplankton to avoid predation risk from visually hunting predators, e.g., fish (Hays 2003; Zaret and Suffern 1976). However, fish are generally size-selective predators, that preferentially feed on prey items with larger sizes
(Brooks and Dodson 1965). In line with this, we expected larger, more visible individuals to remain at deeper depths during the day as compared to smaller individuals. Our observations matched these predictions, as calanoid copepods showed a size-structured depth segregation, where larger individuals were found at deeper depths than smaller ones during the day, which is also consistent with previous studies (Hansson and Hylander 2009b; Holliland et al. 2012). Moreover, smaller individuals staying at shallower depths during the day may also avoid competition with larger conspecifics for food. Similar patterns of vertical stratification have also been observed among zooplankton species in more extreme habitats, such as in Sahara lakelets (Dumont 2019). However, in lakes at higher latitudes or elevation, the deeper distribution of larger individuals likely slows growth and reproduction rates due to cooler temperatures experienced at these depths (Rhode et al. 2001), which may not be the case in our study systems. Instead, residing in deeper waters during the day may enable the Bahamian copepods to better utilize food resources since all investigated blue holes demonstrated deep chlorophyll maxima. This pattern was particularly pronounced in East Twin, where the peak density of calanoid copepods coincided with the depth of the deep chlorophyll maximum at $25 \mathrm{~m}$. However, in our study systems, the deep chlorophyll maxima are likely a result of sinking phytoplankton that accumulate above the halocline, thereby constituting a considerable food patch for zooplankton.

In conclusion, we show that copepods in subtropical blue holes exhibit DVM that allows for protection from visually hunting predators, whereas no response was found to lake-specific differences in UVR transparency. This observation likely resulted from intense UVR with negligible temporal variation at an evolutionary time scale in these systems, leading to photoprotective adaptations among zooplankton. An additional, and non-exclusive, explanation is that as predation drives zooplankton to far deeper waters than needed for being protected from UVR, the escape from one threat (predation) provides protection also from the other (UVR). Hence, in a broader context we show here, for the first time, that if the UVR threat is strong and constant, as is the case at low latitudes, UVR may not be, as might be expected, the major driving force for DVM, since photoprotection may be well established. Therefore, DVM patterns may instead be 
governed by other threats and opportunities, such as predation and food levels. In turn, this suggests that the TRH hypothesis may be less applicable at low, rather than at high latitudes where UVR levels are less predictable. Hence, our study adds to the current knowledge by showing that copepods may use different mixes of threat avoidances, including DVM and photoprotective pigmentation, to handle the local threat situation. This suggests that the major driving mechanism for DVM may vary considerably between systems at low and high latitudes, respectively.

Acknowledgements We thank the Bahamas government for permission to conduct the work and Wilfred Johnson and Matt Jenkins for support in the field.

Author contributions YS, HZ, ML, and L-AH conceived and led the study. YS, HZ, ML, RBL, L-AH, CaB, MŠ, RG, and SDH conducted the field work with help from GEU, JV, NH, VP, KH, PAN, KR, and ChB. All authors have been actively involved in planning the study and provided logistic aid and guidance both during the research expedition and data analysis process. YS conducted the data analyses with help from RBL and L-AH. YS wrote the first version of the manuscript with main contributions from L-AH, RBL, ChB, KH, PAN, and KR. All authors commented and provided valuable input on all versions of the manuscript.

Funding Open access funding provided by Lund University. This study was funded by the Helge Ax:son Johnsons foundation, the China Scholarship Council, the Royal Physiographic Society, the County Govenor Per Westling Memorial Fund, and the Swedish Research Council (VR).

Data availability Authors confirm that the data supporting the results will be made available online if the manuscript is accepted for publication.

\section{Compliance with ethical standards}

Conflict of interest The authors declare that they have no conflict of interest.

Open Access This article is licensed under a Creative Commons Attribution 4.0 International License, which permits use, sharing, adaptation, distribution and reproduction in any medium or format, as long as you give appropriate credit to the original author(s) and the source, provide a link to the Creative Commons licence, and indicate if changes were made. The images or other third party material in this article are included in the article's Creative Commons licence, unless indicated otherwise in a credit line to the material. If material is not included in the article's Creative Commons licence and your intended use is not permitted by statutory regulation or exceeds the permitted use, you will need to obtain permission directly from the copyright holder. To view a copy of this licence, visit http://creativecommons.org/licenses/by/4.0/.

\section{References}

Bayly I (1986) Aspects of diel vertical migration in zooplankton, and its enigma variations. In: Williams WD (ed) De Deckker P. Limnology in Australia. CSIRO Australia, Junk, Melbourne, pp 349-368

Berge J et al (2009) Diel vertical migration of Arctic zooplankton during the polar night. Biol Let 5:69-72. https:// doi.org/10.1098/rsbl.2008.0484

Björnerås C et al (2020) Inland blue holes of the Bahamas chemistry and biology in a unique aquatic environment. Fundam Appl Limnol. https://doi.org/10.1127/fal/2020/ 1330 (in press)

Brooks JL, Dodson SI (1965) Predation, body size, and composition of plankton. Science 150:28-35. https://doi.org/ 10.1126/science. 150.3692 .28

Brüsin M, Svensson PA, Hylander S (2016) Individual changes in zooplankton pigmentation in relation to ultraviolet radiation and predator cues. Limnol Oceanogr 61:1337-1344. https://doi.org/10.1002/lno.10303

Cooke SL, Williamson CE (2006) Positive effects of UV radiation on a calanoid copepod in a transparent lake: do competition, predation or food availability play a role? J Plankton Res 28:171-179

Dumont HJ (2019) Zooplankton vertical migration in two Sahara lakes with contrasting biotic environments. Limnetica 38:95-101

Ekvall MT, Hylander S, Walles T, Yang X, Hansson L-A (2015) Diel vertical migration, size distribution and photoprotection in zooplankton as response to UV-A radiation. Limnol Oceanogr 60:2048-2058. https://doi.org/10.1002/lno. 10151

Fernández CE, Campero M, Uvo C, Hansson L-A (2018) Disentangling population strategies of two cladocerans adapted to different ultraviolet regimes. Ecol Evol 8:1995-2005

Fields DM et al (2014) Infection of the planktonic copepod Calanus finmarchicus by the parasitic dinoflagellate, Blastodinium spp: effects on grazing, respiration, fecundity and fecal pellet production. J Plankton Res 37:211-220. https://doi.org/10.1093/plankt/fbu084

Fischer JM, Olson MH, Theodore N, Williamson CE, Rose KC, Hwang J (2015) Diel vertical migration of copepods in mountain lakes: The changing role of ultraviolet radiation across a transparency gradient. Limnol Oceanogr 60:252-262

Fortier M, Fortier L, Hattori H, Saito H, Legendre L (2001) Visual predators and the diel vertical migration of copepods under Arctic sea ice during the midnight sun. J Plankton Res 23:1263-1278. https://doi.org/10.1093/ plankt/23.11.1263

Gluckman T, Hartney KB (2000) A trophic analysis of mosquitofish, Gambusia hubbsi Breder, inhabiting blue holes on Andros Island, Bahamas Caribbean. J Sci 36:104-111

Hansson L-A (2004) Plasticity in pigmentation induced by conflicting threats from predation and UV radiation. Ecology 85:1005-1016

Hansson L-A, Hylander S (2009a) Effects of ultraviolet radiation on pigmentation, photoenzymatic repair, behavior, and 
community ecology of zooplankton. Photochem Photobiol Sci 8:1266-1275

Hansson L-A, Hylander S (2009b) Size-structured risk assessments govern Daphnia migration. Proc Royal Soc B 276:331-336. https://doi.org/10.1098/rspb.2008.1088

Hansson L-A, Hylander S, Sommaruga R (2007) Escape from UV threats in zooplankton: a cocktail of behavior and protective pigmentation. Ecology 88:1932-1939

Hays GC (2003) A review of the adaptive significance and ecosystem consequences of zooplankton diel vertical migrations. Hydrobiologia 503:163-170

Heinen JL, Coco MW, Marcuard MS, White DN, Peterson MN, Martin RA, Langerhans RB (2013) Environmental drivers of demographics, habitat use, and behavior during a postPleistocene radiation of Bahamas mosquitofish (Gambusia hubbsi). Evol Ecol 27:971-991

Holliland PB, Ahlbeck I, Westlund E, Hansson S (2012) Ontogenetic and seasonal changes in diel vertical migration amplitude of the calanoid copepods Eurytemora affinis and Acartia spp. in a coastal area of the northern Baltic proper. J Plankton Res 34:298-307

Hylander S (2020) Mycosporine-Like amino acids (MAAs) in zooplankton. Mar Drugs 18:72. https://doi.org/10.3390/ md18020072

Hylander S, Larsson N, Hansson L-A (2009) Zooplankton vertical migration and plasticity of pigmentation arising from simultaneous UV and predation threats. Limnol Oceanogr 54:483-491. https://doi.org/10.4319/lo.2009.54.2.0483

Kessler K, Lockwood RS, Williamson CE, Saros JE (2008) Vertical distribution of zooplankton in subalpine and alpine lakes: ultraviolet radiation, fish predation, and the transparency-gradient hypothesis. Limnol Oceanogr 53:2374-2382

Lampert W (1989) The adaptive significance of diel vertical migration of zooplankton. Funct Ecol 3:21-27

Lampert W (1993) Ultimate causes of diel vertical migration of zooplankton: new evidence for the predator-avoidance hypothesis. Arch Hydrobiol Beiheft Ergeb Limnol 39:79-88

Lee $\mathrm{M}$ et al (2019) Low-latitude zooplankton pigmentation plasticity in response to multiple threats. Royal Soci Open Sci 6:190321

Leech DM, Padeletti A, Williamson CE (2005) Zooplankton behavioral responses to solar UV radiation vary within and among lakes. J Plankton Res 27:461-471

Leech DM, Williamson CE (2001) In situ exposure to ultraviolet radiation alters the depth distribution of Daphnia. Limnol Oceanogr 46:416-420

Loose CJ (1993) Daphnia diel vertical migration behavior: response to vertebrate predator abundance. Ergebnisse der Limnologie 39:29-36

Loose CJ, Dawidowicz P (1994) Trade-offs in diel vertical migration by zooplankton: the costs of predator avoidance. Ecology 75:2255-2263
Martynova DM, Gordeeva AV (2010) Light-dependent behavior of abundant zooplankton species in the White Sea. J Plankton Res 32:441-456

Mylroie JE, Carew JL, Moore AI (1995) Blue holes: definition and genesis. Carbonates Evaporites 10:225-233. https:// doi.org/10.1007/bf03175407

Overholt EP, Rose KC, Williamson CE, Fischer JM, Cabrol NA (2016) Behavioral responses of freshwater calanoid copepods to the presence of ultraviolet radiation: avoidance and attraction. J Plankton Res 38:16-26

Pinheiro J, Bates D, DebRoy S, Sarkar D, R Development Core Team (2018) nlme: Linear and Nonlinear Mixed Effects Models. R package version 3.1-137.

R Core Team (2018) R: A language and environment for statistical computing. R Foundation for Statistical Computing, Vienna, Austria. URL https://www.R-project.org/ Vienna, Austria

Rejas D, De Meester L, Ferrufino L, Maldonado M, Ollevier F (2007) Diel vertical migration of zooplankton in an Amazonian várzea lake (Laguna Bufeos, Bolivia). Stud Neotrop Fauna Environ 42:71-81

Rhode SC, Pawlowski M, Tollrian R (2001) The impact of ultraviolet radiation on the vertical distribution of zooplankton of the genus Daphnia. Nature 412:69

Ringelberg J (1991) A mechanism of predator-mediated induction of diel vertical migration in Daphnia hyalina. J Plankton Res 13:83-89

Scully N, Lean D (1994) The attenuation of ultraviolet radiation in temperate lakes. Ergeb der Limnol 43:135-135

Tartarotti B, Trattner F, Remias D, Saul N, Steinberg CE, Sommaruga R (2017) Distribution and UV protection strategies of zooplankton in clear and glacier-fed alpine lakes. Sci Rep 7:4487

Tiberti R, Barbieri M (2011) Evidences of zooplankton vertical migration in stocked and never-stocked alpine lakes in Gran Paradiso National Park (Italy). Oceanol Hydrobiol Stud 40:36-42

Tiberti R, Iacobuzio R (2013) Does the fish presence influence the diurnal vertical distribution of zooplankton in high transparency lakes? Hydrobiologia 709:27-39

Williamson CE, Fischer JM, Bollens SM, Overholt EP, Breckenridge JK (2011) Toward a more comprehensive theory of zooplankton diel vertical migration: integrating ultraviolet radiation and water transparency into the biotic paradigm. Limnol Oceanogr 56:1603-1623

Worthington EB (1931) Vertical movements of fresh-water Macroplankton. Int Rev der gesamten Hydrobiol Hydrogr 25:394-436. https://doi.org/10.1002/iroh.19310250510

Zaret TM, Suffern JS (1976) Vertical migration in zooplankton as a predator avoidance mechanism. Limnol Oceanogr 21:804-813

Publisher's Note Springer Nature remains neutral with regard to jurisdictional claims in published maps and institutional affiliations. 